\title{
O Caráter dinâmico da Sequência didática de gêneros em entrelaçamento com a Escrita Criativa
}

\author{
The dynamic character of the didactic sequence of genres in interlacing with creative \\ writing
}

\author{
Marilúcia dos Santos Domingos Striquer ${ }^{*}$ \\ Universidade Estadual do Norte do Paraná (UENP) \\ Cornélio Procópio, Paraná, Brasil \\ Aline Regina Lemes de Sene** \\ Secretaria de Educação do Estado do Paraná (SEED) \\ Cornélio Procópio, Paraná, Brasil
}

\begin{abstract}
Resumo: Este artigo tem o objetivo de apresentar uma proposta de intervenção didática construída pelos preceitos da metodologia da sequência didática de gêneros em entrelaçamento com dinâmicas sugeridas pela Escrita Criativa, bem como tecer algumas considerações sobre a contribuição da trama no desenvolvimento de capacidades de linguagem de alunos do $6^{\circ}$ ano do ensino fundamental para a produção escrita do conto maravilhoso. Exatamente diante do referido gênero, pertencente à esfera literária, a junção das proposições da Escrita Criativa com as da vertente didática do Interacionismo Sociodiscursivo visou suporte para a construção de atividades direcionadas ao trabalho com o processo de criação artística e de incentivo à condição de autoria. Os resultados demonstram que a metodologia da sequência didática contribui à medida que propõe um conjunto de atividades, com objetivos delimitados, organizado e sistematizado com a finalidade de aprimorar as práticas linguageiras; a Escrita Criativa fornece preceitos que incentivam o desenvolvimento da imaginação e da criatividade do aluno, imprescindível para a composição do conto maravilhoso.
\end{abstract}

Palavras-chave: Conto maravilhoso. Escrita Criativa. Gêneros textuais. Sequência didática.

\begin{abstract}
This article aims to present a proposal of didactic intervention built up by the precepts of the methodology of the didactic sequence of genres in interlacing with dynamics suggested by Creative Writing, and to make some considerations about the contribution of the interlacing in the development of language skills of students from the 6th grade of basic education to the writing production of the wonder tale. In view of the mentioned genre, belonging to the literary sphere, the combination of the propositions of Creative Writing with the didactic aspects of Sociodiscursive Interactionism aimed to support the construction of activities directed to the work with the process of artistic creation and to encourage the condition of authorship. The results show that the communion between the two methodologies allows the approach of the genre as a whole; the didactic sequence methodology contributes to extent the proposed set of activities, with defined objectives, organized and systematized with the purpose of improving the language practices; the Creative Writing provided techniques and precepts that encourage the development of the student's imagination and creativity, which are essential for the composition of the wonder tale.
\end{abstract}

Keywords: Wonder tale. Writing. Textual genre. Didactic sequence.

*Doutoda em Estudo da Linguagem. Professora da Universidade Estadual do Norte do Paraná (UENP). Bolsista produtividade em pesquisa pela Fundação Araucária do Paraná (Prot. 49372). marilucia@uenp.edu.br.

** Mestre em Letras pelo Programa de Mestrado Profissional em Letras da Universidade Estadual do Norte do Paraná (UENP). Professora da Secretaria de Educação do Estado do Paraná. alinerls@hotmail.com. 


\section{INTRODUÇÃO}

Defende a vertente didática do Interacionismo Sociodiscursivo (ISD) que, para que um gênero se torne um objeto de ensino na escola, é preciso ações didáticas distintas que envolvam, de forma indissolúvel, teoria e prática, na busca de conhecer: quais são as dimensões que formam um gênero textual e quais delas são ensináveis; quais dos elementos que formam as dimensões que ainda não foram apreendidas pelos alunos; que atividades podem organizar de maneira sistemática o processo de ensino e aprendizagem de um gênero; entre outros aspectos (DOLZ; SCHNEUWLY, 2004; DOLZ; NOVERRAZ; SCHNEUWLY, 2004; MACHADO, 2005; MACHADO; CRISTOVÃO, 2006). Em decorrência, a sugestão é para construção de procedimentos que formam o que os autores denominam de engenharia didática de gêneros, que, em síntese, diz respeito à elaboração de modelos didáticos e de sequências didáticas de gêneros (SDG). Conforme Dolz, Noverraz e Schneuwly (2004), a proposta do trabalho com a engenharia didática é uma forma de organização da ação pedagógica que possibilita o desenvolvimento de capacidades de linguagem dos alunos para as práticas discursivas da produção de texto, da leitura e da análise linguística, a fim de que os discentes atuem na sociedade de forma ativa, fazendo uso dos mais diversos gêneros textuais como instrumentos de interação social.

No Brasil, tais procedimentos para elaboração tanto do modelo didático quanto da SDG foram recebendo, ao longo do tempo, diferentes configurações, trazendo, segundo Magalhães e Cristovão (2018, p. 18), "inevitáveis mudanças e ressignificação para o constructo". Exatamente nesse sentido, para a construção de uma proposta de intervenção didática ${ }^{1}$, norteada pela metodologia da SDG, que teve como objetivo desenvolver capacidades de linguagem de alunos do $6^{\circ}$ ano do ensino fundamental, de uma escola da rede pública de ensino, para a produção escrita do conto maravilhoso, foi necessário que realizássemos algumas adaptações na proposta original da SDG. Das adaptações, destacamos, neste trabalho, um entrelaçamento nos procedimentos que configuram a SDG e os projetados pela Escrita Criativa (EC) (PAVANI, MACHADO, 2003; CLAVER, 2004; MANCELOS, 2013; GONZAGA E TUTILIAN, 2015).

Diante das especificidades de gênero que elegemos como eixo condutor para o trabalho com a leitura e a produção textual dos alunos do $6^{\circ}$ ano do ensino fundamental, o conto maravilhoso, que está inserido na esfera literária, vimos como ponto motivador a afirmativa de Tauveron (2014) de que ao inserirmos o texto literário em sala de aula, como conteúdo de ensino e aprendizagem das práticas de leitura e produção textual dos alunos, não se pode pretender formar um aluno escritor, no âmbito profissional. O objetivo deve ser possibilitar ao discente o contato com o processo de criação artística e incentivar sua condição de autoria, promovendo que ele se apresente perante o que escreve.

\footnotetext{
${ }^{1}$ A referida proposta é parte integrante da dissertação de Mestrado de Sene (2019), a qual está vinculada ao projeto "Gêneros discursivos/textuais: dos documentos prescritivos à sala de aula", coordenado pela professora Dra. Marilúcia dos Santos Domingos Striquer, subsidiado pela Fundação Araucária do Paraná, pela Bolsa Produtividade em Pesquisa.
} 
Assim, em pesquisa sobre as propostas de ensino da língua portuguesa destinada à educação básica, tendo como eixo organizador gêneros da esfera literária, centrados, principalmente, no trabalho com a prática discursiva da produção textual, deparamo-nos com trabalhos muitos significativos sustentados pela metodologia da Escrita Criativa (EC). De acordo com Mancelos (2007, p. 14), a EC pode ser definida como "[...] o estudo crítico, a transmissão e o exercício de técnicas utilizadas por escritores e ensaístas de diversas épocas, culturas e correntes, para a elaboração de textos literários ou mesmo não literários". É, portanto, uma abordagem relacionada com o ensino da escrita que incorre na elaboração de técnicas e oficinas voltadas à prática da escrita, em especial, da escrita literária. Logo, consideramos que os preceitos teórico-metodológicos da EC poderiam nos dar suporte para construção de atividades que compõem nossa SDG destinada à formação do aluno-autor, termo cunhado por Tauveron (2014).

Vale ainda salientar que o mais novo documento prescritivo da ação docente, a Base Nacional Comum Curricular (BNCC) (BRASIL, 2017), ao considerar o trabalho com as práticas de linguagem situadas, busca categorizá-las em campos de atuação, de modo a garantir o acesso às dimensões formativas de linguagem, dentre as quais figurase o campo artístico-literário. O documento elenca dez competências específicas de Língua Portuguesa para o ensino fundamental, dentre as quais destacamos a capacidade do aluno de,

[...] envolver-se em práticas de leitura literária que possibilitem o desenvolvimento do senso estético para fruição, valorizando a literatura e outras manifestações artístico-culturais como formas de acesso às dimensões lúdicas, de imaginário e encantamento, reconhecendo o potencial transformador e humanizador da experiência com a literatura. (BRASIL, 2017, p. 85).

Também a Diretriz Curricular do Estado do Paraná - Língua Portuguesa (DCELP) apresenta a literatura como arte que humaniza/transforma o homem e a sociedade por meio de suas funções psicológica, formadora e social. A função psicológica "permite ao homem a fuga da realidade, mergulhando num mundo de fantasias, o que lhe possibilita momentos de reflexão, identificação e catarse.” (PARANÁ, 2008, p. 57). Sobre a função formadora, o documento expõe que "a literatura por si só faz parte da formação do sujeito, atuando como instrumento de educação, ao retratar realidades não reveladas pela ideologia dominante." (PARANÁ, 2008, p. 57). E, a função social corresponde "à forma como a literatura retrata os diversos segmentos da sociedade, é a representação social e humana.” (PARANÁ, 2008, p. 58). Logo, justificamos nossa delimitação do conto maravilhoso como eixo organizador da proposta de intervenção didática destinada ao $6^{\circ}$ ano, etapa inicial do ensino fundamental, em que o aluno préadolescente passa a se inserir cada vez mais na sociedade, refletindo sobre as relações existentes no mundo e sobre quem ele é no mundo.

Diante do contexto e preceitos expostos, esclarecemos que este artigo tem como objetivo apresentar uma proposta de intervenção didática elaborada e implementada em sala de aula, a qual foi construída no entrelaçamento das dinâmicas propostas pela Escrita Criativa na formação das oficinais que compõem a SDG, bem como, 
intencionamos relatar, de forma breve, algumas contribuições do entrelaçamento em questão.

\title{
2 ESCRITA CRIATIVA
}

\author{
Para Silva (2013, p. 17), a EC,
}

[...] pode ser perspectivada como um meio de aprendizagem da escrita. Esta proposta de trabalho convida os estudantes a expressarem, de uma forma mais personalizada, alguns pensamentos ou perspectivas que possuem relativamente a temas mais fantasiosos ou reais. Através da construção de textos narrativos, poéticos e dramáticos, os estudantes têm uma vasta panóplia de possibilidades de exercícios para exercitarem as suas potencialidades criativas. O docente tem ao seu dispor um vasto leque de propostas de trabalho para que os seus alunos desenvolvam as suas competências de escrita, aplicando os conhecimentos gramaticais adquiridos anteriormente. A utilização prática desta metodologia configurar-se-á em oficinas de escrita que podem ser de índole teórica - quando o docente fornece técnicas de escrita para que os estudantes não careçam de noções de estratificação textual, por exemplo - e também poderão ser de carácter mais prático, nas quais o professor fornecerá as temáticas e as indicações para que haja produção de texto.

Assim, constituída por um conjunto de propostas de trabalhos, ou técnicas, que podem ser adotados por pessoas que desejavam aprimorar a prática de produção de textos de caráter literário, a EC se disseminou no contexto escolar como potencial metodologia, conforme assertiva de Sena-Lino (2012). Para o autor, as técnicas permitem "[...] a qualquer pessoa, independentemente, do seu background, desenvolver as suas capacidades de escrita" (SENA-LINO, 2012 apud FERNANDES, 2012, p. 45). O que vai, conforme o autor, de encontro há uma vertente que nega a necessidade e a validade do trabalho com a escrita do texto literário na escola sob a premissa de que, devido seu caráter artístico, o processo de criação literária não pode ser objeto de sistematização. Vertente, sob nosso ponto de vista, que acredita na "inspiração" que confere ao autor um caráter "divino" de detentor da habilidade da escrita, e acaba dividindo as pessoas entre "os talentosos" e "os não talentosos", o que, para Assis Brasil, 2003, p. 74), é uma “[...] partição inaceitável num mundo que se esforça, para sem discriminações, assimilar e a integrar as diferenças e as minorias". A esse respeito, SenaLino (2012) deixa explícito de que é preciso refutar essa ideia da não possibilidade de sistematização do ensino da escrita literária, sua assertiva é a de que é preciso,

[...] deixar de acreditar na 'inspiração', em primeiro lugar. Nem todas as escritas de livros vêm com emoções associadas, grandes intensidades de pele interior, para ajudar a escrever seja o que for. E com o andar do tempo e da experiência, é como o amor: não é preciso senti-lo para ele ser real. Em seguida, ter um plano e um horário. Sem um hábito de escrita e uma luta diária para isso, não se vai a lado nenhum. Escrever, mesmo que no final o balde do lixo seja melhor. Está-se a 
estabelecer hábitos, a pensar no que se escreve, e a dobrar e a arrumar a linguagem, ou ainda mais, a bater no ferro da linguagem para depois ficar quente. (SENALINO, 2012 apud FERNANDES, 2012, p. 47).

Sob essa perspectiva é que compreendemos a premissa de Bakhtin (2003) de que "falamos apenas através de determinados gêneros do discurso, isto é, todos os nossos enunciados possuem formas relativamente estáveis e típicas de construção do todo." (BAKHTIN, 2003, p. 282). Cada gênero, ao ser abordado em suas especificidades, é passível de se tornar objeto de ensino, o que converge com os preceitos da EC que postula um trabalho diferenciado para cada gênero literário e não literário, tendo em vista as características típicas cada um deles. Quando tratamos do texto literário, por se enquadrar na categoria de gênero secundário na perspectiva bakhtiniana, compreendemos que ele surge "nas condições de um convívio cultural mais complexo e relativamente muito desenvolvido e organizado" (BAKHTIN, 2003, p. 263), o que demanda um trabalho didático mais apurado e sistematizado, com procedimentos específicos, que eleve o sujeito a um nível linguístico mais desenvolvido.

Diante do desafio da necessidade de uma metodologia adequada que aborde o texto literário em todas as suas peculiaridades, adotamos, em conjunto com a metodologia da SDG a proposta da EC. Nosso interesse justifica-se, entre outros pontos já mencionados, por se tratar de uma proposta de trabalho de análise do texto e dos sentidos que estão nele em construção, não se valendo apenas da subjetividade ou imaginação do autor, mas da racionalidade necessária para a organização dos sentidos entrelaçados com a organização textual. Leitão (2008) afirma que

[...] a escrita criativa tem sempre uma dupla dimensão - a do conteúdo e a da forma. Enquanto proposta de trabalho dirigida a estudantes, a escrita criativa não pretende senão desenvolver neles uma prática de escrita personalizada e eficaz, tanto ao nível da substância, como ao nível da forma (LEITẪ, 2008, p. 32).

Para Rodrigues (2015), “a base desta metodologia está na análise e discussão de textos literários, seguida da produção, discussão e revisão textual." (RODRIGUES, 2015, p. 05). O que se concilia ao esquema originalmente sugerido por Dolz, Noverraz e Schneuwly (2004) para uma SDG: apresentação da situação; produção inicial; módulos; produção final - conforme apresentamos a seguir.

\section{O ENTREÇAMENTO}

$\mathrm{Na}$ primeira etapa de trabalho com o texto literário, a EC propõe a leitura e discussão de textos que servirão como modelos para o aluno, não visando a simples imitação, mas para que o discente tenha exemplares onde possa observar e (re)conhecer os elementos que constituem o texto. Etapa totalmente conciliadora com o primeiro momento de uma SD (DOLZ; NOVERRAZ; SCHNEUWLY, 2004). Na SDG, a Apresentação da situação visa a contextualizar a proposta de produção e exemplificá-la a partir da leitura de exemplares do gênero em processo de trabalho; destacamos a 
relevância do trabalho com textos reais, uma vez que "a língua passa a integrar a vida através de enunciados concretos." (BAKHTIN, 2003, p. 265). Ainda nessa etapa da SDG, o aluno tem acesso ao conjunto de elementos que formam o gênero: o propósito comunicativo que dá origem a interação, a situação de comunicação onde está inserido o gênero, o contexto de produção e a infraestrutura textual que compõem o gênero (BRONCKART, 2009). O que defende a vertente didático do ISD é que as ações e atividades que formam a SDG levem o aluno a se apropriar do gênero, desenvolvendo capacidades de linguagem para mobilizá-los nos contextos de interações em que eles existem.

As capacidades de linguagem, de acordo com Schneuwly e Dolz (2004), são aptidões que o indivíduo tem, ou deve desenvolver, para sua ação social, das quais destacamos: capacidade de ação - reconhecimento do contexto de produção dos textos; capacidade discursiva- mobilização de referências sobre a organização interna de um gênero para construir e interpretar os sentidos do texto; capacidade linguísticodiscursiva - reconhecimento das unidades linguísticas que organizam os sentidos do texto.

Como um segundo momento, no esquema da EC, inicia-se o processo de produção de texto pelo aluno, o que também preconiza a SDG. A primeira produção, para ambas as propostas, é um instrumento de diagnóstico para o professor.

Como terceira etapa, a EC sugere discussão do texto produzido, tal discussão pode ser absorvida na SDG na etapa do trabalho com os módulos, uma vez que o objetivo é que o aluno tenha a oportunidade de aperfeiçoar o texto produzido. Portanto, nos módulos, as técnicas e dinâmicas elaboradas por autores como Pavani e Machado (2003), Claver (2004), Mancelos (2013), Gonzaga e Tutikian (2015), que formam a metodologia da EC, com as devidas adaptações, transformações necessárias diante de cada proposta de trabalho pedagógico, podem ser trabalhadas na SDG.

A etapa da revisão e a reescrita, proposta no esquema da EC desempenham um papel fundamental no processo de produção de texto, pois são momentos de adequação ou redirecionamento aos objetivos da escrita e, sendo assim, é importante que o aluno conheça esses objetivos: saiba para que escreve e, em especial, para quem escreve, porque "[...] são esses leitores potenciais que, indiretamente, estimularão o aluno-autor a buscar um texto de maior qualidade [...].” (GUSSO; DALLA-BONA, 2014, p. 83).

O processo de revisão e de reescrita apresentado no esquema da EC compõe nossa SDG no trabalho com a produção final do aluno. Para esse momento, a metodologia da EC sugere, além da correção feita pelo professor, a autocorreção a correção entre pares a partir de uma grade de correção elaborada pelo docente de acordo com os objetivos de ensino. Conforme Magalhães e Cristovão (2018, p. 48), a revisão pode ser considerada, atualmente, como componente da SDG.

A seguir, apresentamos como o entrelaçamento constitui as atividades que formam nossa SDG. 


\section{ENCAMINHAMENTOS E CONTRIBUIÇÕES}

No momento da elaboração das atividades que formam nossa SDG, compreendemos que as técnicas sugeridas pela EC poderiam compor a SDG em diversos momentos, não apenas na construção e implementações dos módulos, conforme prevemos no momento de estudo da EC e como relatamos na seção anterior. Logo, das 14 oficinas que formam a SDG, atividades construídas com base nas técnicas da EC estão presente em quatro delas, com a elaboração de cinco dinâmicas. De forma sintética, realizamos uma primeira apresentação das oficinas, para que seja possível conhecer a SDG elaborada e implementada:

Quadro 1: Oficinas que compõem a SDG

\begin{tabular}{|l|l|}
\hline Oficina & Atividade em adaptação de técnicas da EC \\
\hline $\begin{array}{l}\text { 1.Reconhecendo as relações sociais } \\
\text { problemáticas instituídas na sociedade }\end{array}$ & Dinâmica "Caixa de sentimentos" \\
\hline 2.Reconhecendo do projeto de classe & \\
\hline 3.Conhecendo uma escritora de contos & \\
\hline $\begin{array}{l}\text { 4.Conhecendo os contos de Ricardo de } \\
\text { Azevedo }\end{array}$ & Dinâmica "Caixa cenário". \\
\hline $\begin{array}{l}\text { 5.Apresentação das características discursivas } \\
\text { do gênero (parte I) }\end{array}$ & \\
\hline $\begin{array}{l}\text { 6.Apresentação das características discursivas } \\
\text { do gênero (parte II) }\end{array}$ & Dinâmica "Texto quebra-cabeça". \\
\hline $\begin{array}{l}\text { 7.Apresentação das características linguístico- } \\
\text { discursivas do gênero (parte I) }\end{array}$ & \\
\hline $\begin{array}{l}\text { 8.Apresentação das características linguístico- } \\
\text { discursivas do gênero (parte II) }\end{array}$ & \\
\hline 9.Desenvolvendo o conto & $\begin{array}{l}\text { Dinâmica "ABC do Era uma vez" (banco } \\
\text { de palavras) } \\
\text { Dinâmica "Festa à fantasia”. }\end{array}$ \\
\hline 10.Produção inicial & \\
\hline 11.Revisando & \\
\hline 12.Reescrevendo & \\
\hline 13.Ilustrando & \\
\hline 14.Finalizando a interação & \\
\hline
\end{tabular}

Fonte: elaborado pelas pesquisadoras

A seguir, apresentamos as oficinas que foram elaboradas e sustentadas no entrelaçamento com as propostas da EC, em consonância com o objetivo deste artigo.

Oficina 1. Reconhecendo as relações sociais problemáticas instituídas na sociedade. Objetivo: despertar o interesse dos alunos pelas temáticas abordadas pelo gênero; propor reflexão sobre as relações humanas e os sentimentos que podem ser discutidos no conto maravilhoso; promover o contato dos alunos com o gênero discursivo/textual. Entre as atividades propostas, destacamos: 1. Roda de conversa: dinâmica "Caixa de Sentimentos"; 2. Leitura do conto "A mulher dourada e o menino 
careca" (AZEVEDO) e identificação da temática; 3. Produção de um mural de sala com os possíveis temas a serem abordados nos contos maravilhosos.

Para a dinâmica "Caixa de sentimentos", as instruções no Caderno pedagógico², parte integrante da dissertação de mestrado de Sene (2019), são para que o professor inicie o trabalho a partir do princípio fundador do gênero conto maravilhoso: constituído por temas universais; com a função social de fazer refletir sobre relações humanas. Sugestão:

Professor, conduza a dinâmica "Caixa dos sentimentos: que sentimento é esse?".

Material: uma caixa de papelão pequena que contenha pedaços de papéis com nomes de sentimentos e atitudes abordados tematizados nos contos maravilhosos: amor, ódio, vingança, tristeza, inveja, ganância, alegria, paixão, curiosidade, maldade, bondade, traição, entre outros. O ideal é que haja um papel para cada aluno.

Procedimento: explique aos alunos que dentro da caixa estão alguns dos sentimentos e atitudes mais comuns no relacionamento humano, e que a tarefa deles é sortear um papel e tentar definir a palavra sorteada por meio de mímica ou de exemplos práticos, mas o nome propriamente dito do sentimento ou atitude não pode ser revelado. Os demais alunos da sala devem adivinhar qual é o sentimento ou atitude.

O objetivo é que os alunos reflitam a partir dos gestos ou dos exemplos práticos sobre como esses sentimentos e atitudes afetam a vida das pessoas.

Finalizada a dinâmica, questione os alunos se é importante falar sobre esses sentimentos e quais são os textos que favorecem que as pessoas falem sobre eles. Apresentar, assim, o conto maravilhoso como uma possibilidade de sensibilização para o tema (Atividade A). Em seguida, promover a leitura compartilhada do conto "A mulher dourada e o menino careca", de Ricardo Azevedo. Após a leitura, questionar os alunos sobre quais sentimentos eles observaram na história. As respostas apresentadas, bem como os sentimentos explorados na dinâmica, podem compor um mural intitulado: Sobre o que falam os contos maravilhosos. (SENE, 2019, p. 12).

\section{Atividade A}

Você participará de uma dinâmica chamada "Caixa dos sentimentos: que sentimento é esse?”, fique atento às orientações do seu professor. Após a dinâmica participe da discussão:

Quais sentimentos apareceram na dinâmica? Escreva aqui:

Você acha importante falarmos e refletirmos sobre esses sentimentos? Por quê? Converse sobre isso com seus colegas e professor.

Quais textos podem propor a reflexão sobre esses e outros sentimentos? Assinale as alternativas: () receita culinária ( ) conto maravilhoso ( ) poema ( ) notícia de jornal ( ) manual de instrução ( ) letra de música (SENE, 2019, p. 28).

${ }^{2}$ Disponível em: www.uenp.edu.br/profletras 
A Oficina 4. Conhecendo os contos de Ricardo de Azevedo - tem o objetivo de trabalhar com as caraterísticas do contexto de produção do gênero textual. Atividades propostas: 2. Contação da história "Dona Boa-Sorte mais dona Riqueza" (AZEVEDO), utilizando a dinâmica "Caixa cenário". Sugestão:

Professor: Após a reflexão sobre as características que circundam os contos de Ricardo Azevedo, propomos a contação da história "Dona Boa-Sorte mais dona Riqueza" (AZEVEDO), e a utilização da técnica "Caixa cenário" para enriquecer o momento de leitura do texto.

\section{Como utilizar a Caixa Cenário}

Material: caixa de papelão caracterizada com o cenário da história; fantoches dos personagens.

Procedimento: os alunos podem ser convidados a contarem a história, manipulando os fantoches. O professor pode atuar como narrador, conduzindo a história. Para mais informações e orientações sobre a técnica acesse:

https://www.youtube.com/watch?v=gA9PQxWncSE

https://www.youtube.com/watch?v $=$ pR4CS3tJH2I

Entregar aos alunos a Atividade $\mathbf{F}$ que tem o objetivo verificar a compreensão do texto, e se os alunos apreenderam as características contextuais que o formam. (SENE, 2019, p. 14-15).

\section{Atividade F}

Após a leitura do texto "Dona Boa-Sorte mais Dona Riqueza", responda:

1. O texto que você leu é: ( ) um poema ( ) um convite ( ) um conto maravilhoso ( ) uma lenda

2. O objetivo desse texto é: (A) fazer refletir sobre a relação entre as pessoas (B) informar (C) passar uma lição de moral (D) convidar

3. Marque somente as características desse texto.

( ) Pode ter como personagens pessoas do povo e, às vezes, seres extraordinários (fadas, bruxas etc.).

( ) Seus personagens são animais.

( ) Fazem parte da tradição oral e ganham versões à medida que são recontados.

4. Releia o texto e depois responda.

a) Personagem é quem participa da história. Quais as personagens desse texto?

b) De acordo com o texto, como vivia o homem?

c) O que o homem sempre fazia ao acordar?

d) Como se chamavam as mulheres que apareceram querendo ajudar o camponês trabalhador?

e) Como Riqueza disse que ajudaria o homem?

f) Ao ter dinheiro, o homem resolveu seus problemas?

g) Você acredita que dinheiro resolve tudo? Por quê?

h) As personagens que aparecem na história existem, de alguma forma, na vida real? 
5. Após todas essas reflexões sobre o conto, responda: Qual é temática abordada no texto? (SENE, 2019, p. 33-36)

Para que pudéssemos constatar contribuições na inclusão de técnicas da EC na SDG, evidentemente, todas as ações pedagógicas, as atividades que compõem a SDG, os encaminhamentos e reencaminhamentos, as atividades que foram construídas e implementadas diante das necessidades, no momento da implementação da SDG, foram consideradas. Porém, como nos atemos neste trabalho apenas em focalizar o entrelaçamento realizado entre as metodologias, nossos apontamos são para essa questão. Assim, para o trabalho com a temática que constitui o gênero textual conto maravilhoso e a função social do gênero, as atividades construídas em adaptação as propostas por autores da EC auxiliaram no desenvolvimento das capacidades de ação dos alunos (SCHNEUWLY; DOLZ, 2004; LOUSADA, 2007), as quais estão relacionadas ao trabalho de construção e reconhecimento da função social do gênero, de seu contexto de produção. E no caso do conto maravilhoso, que traz à tona a questão dos conflitos originários do viver em sociedade, como aponta Coelho (2003), é importante salientar que comungamos com Silva (2016), que quando se fala em função social da literatura, não é possível limitar os textos literários como de denúncia social, é preciso pôr em evidência o caráter humanizador que os constitui. Segundo Candido (1995, p. 249), humanizar é "confirmar no homem aqueles traços que reputamos essenciais", como a reflexão; é trabalhar "o afinamento das emoções", dando condições ao indivíduo de buscar compreender os problemas da vida; é promover a consciência da "complexidade do mundo e dos seres"; do "senso de humor"; do "senso de beleza", da "boa disposição para com o próximo".

As produções finais dos alunos participantes da SDG demonstram, dentro das condições reais de um texto produzido por um aluno de sexto ano, um pré-adolescente, de 11 a 12 anos, temáticas ligadas às interações das quais participam esses alunos: conflitos na convivência familiar e com colegas na escola e em outros contextos: intolerância, injustiça, humildade, amizade, abandono; e temas ligados aos debates sociais propostos nas mídias e na escola: feminismo, entre outros. Isto é, os discentes trataram em seus contos maravilhosos do caráter edificante do gênero (CÂNDIDO, 1995), de forma a neles exprimirem angústias pessoais e visões particularizadas sobre o mundo (PAVANI; MACHADO, 2003), empregando elementos do maravilhoso (COELHO, 2003), como pode ser conferido no exemplar do gênero que transcrevemos mais adiante.

Da Oficina 4. Conhecendo os contos de Ricardo de Azevedo - destacamos o fato de que as atividades foram construídas com a intenção de levar o aluno a compreender o processo de criação de uma história e quem é aquele que escreve textos literários. A atividade elaborada foi: 1. Apresentação do autor por meio do vídeo "Ricardo Azevedo e suas obras".

Professor: Iniciar apresentando o vídeo "Escritor Ricardo Azevedo - vida e obra", disponível em https://www.youtube.com/watch?v=mzz25a19-UE. Após a apreciação do vídeo, conduzir a discussão (Atividade E). 


\section{Atividade E}

[...] Após o vídeo, participe da discussão seguindo o roteiro de perguntas:

Como foi a infância do autor?

O que na infância influenciou Azevedo a se tornasse um escritor?

Você acredita que para ser um bom escritor é necessário, antes, ser um bom leitor?

Sobre o que Azevedo escreve? O que o motivou a escolher esses temas?

Ele escreve pensando em qual público?

Fique atento: Conhecer o autor e seu projeto de escrita nos ajuda a compreender melhor o texto! (SENE, 2019, p. 33-34).

Antes de comentarmos a Oficina 4, abordamos a Oficina 3. Conhecendo uma escritora de contos - que teve como objetivos: Conhecer uma escritora local e o seu processo de criação; identificar o contexto de criação dos contos.

Professor: para esta etapa orientamos um trabalho para que os alunos elaborarem perguntas direcionadas à palestrante. Da mesma forma, a palestrante deve ser orientada a:

Relatar como ocorre o processo de criação das obras;

Apresentar as suas obras;

Ler alguns contos de sua autoria enfatizando os problemas sociais que envolvem o conteúdo temático.

Previamente, instrua os alunos a elaborarem perguntas direcionadas à escritora para que possam interagir durante a palestra (Atividade D). Instrua os alunos a realizarem anotações no decorrer da palestra identificando as ações realizadas pela palestrante no processo de criação dos contos; o contexto de produção dos contos (em que lugar e momento a escritora produz seus contos, onde publica); as temáticas que são abordadas nos contos da autora; o motivo da autora ter escolhido do conto maravilhoso para falar sobre as referidas temáticas.

Após a palestra, retomar as anotações realizadas pelos alunos e sistematizar as informações coletadas em forma de cartaz. (SENE, 2019, p. 14-15).

\section{Atividade D}

Você conhece algum escritor ou escritora de contos?

Sabe como eles escrevem? Quando e onde produzem seus contos? Onde publicam? Por que escrevem? Sobre o que escrevem?

Teremos o prazer de receber uma escritora de contos para uma conversa e é importante que você se prepare para esse momento. Reúna-se com um colega e elabore perguntas direcionadas à escritora. Qual é a sua curiosidade sobre o ofício de escrever contos?

Durante a palestra fique atento à fala da escritora e anote o que achar interessante:

Após a palestra: Vamos compartilhar as anotações que fizeram. Preste atenção à fala dos seus colegas e espere sua vez para falar. Assim todos se entendem! (SENE, 2019, p. 31-33). 
A forma de apresentação do autor Ricardo Azevedo (Oficina 4) e da escritora local (Oficina 3), aproximando os autores físicos dos alunos ressignificou o papel social de um escritor de contos maravilhosos. Deixando o autor de ser aquele ser afastado da realidade dos alunos, aquele que vive em um mundo de outras experiências e vivências, motivando, assim, a formação do aluno-autor, termo cunhado por Tauveron (2014), escritores de textos literários que sabem adotar a postura de autor em um ambiente que se requer essa capacidade.

Conforme defende (SILVA, 2016, p. 16),

[...] os estudos da EC, que aborda o texto em seu processo de criação, muito colabora no desenvolvimento da habilidade leitora e escritora do aluno em relação ao texto literário. Assim, ele poderá se reconhecer na subjetividade de sua escrita como um sujeito histórico e social, portanto, não alienado, mais humano, mais sensível ao outro, ao mundo e a si mesmo.

Nos contos maravilhosos produzidos pelos alunos é possível identificar o emprego da subjetividade, os discentes apresentam-se como participantes do mundo e das relações de conflito existentes na sociedade.

Oficina 6. Apresentação das características discursivas do gênero (parte II) - teve como objetivo trabalhar os momentos da narrativa, fases constituintes da planificação textual do conto maravilhoso e seu funcionamento discursivo. Atividades: 1. Leitura compartilhada do conto "Moço bonito imundo" (AZEVEDO); 2. Planificação dos momentos da narrativa; 3. Composição do mural com esquema produzido coletivamente; 4. Dinâmica "Texto quebra-cabeça" - para que os alunos ordenem a sequência narrativa. Sugestão:

Professor: Oriente a leitura compartilhada do conto "Moço bonito imundo".

Entregar aos alunos a Atividade H. Exponha a explicação apresentada no caderno e auxilie os alunos na resolução da atividade.

Dando continuidade à produção do mural (memória das aprendizagens), reproduza o esquema apresentado no Caderno do aluno e fixe-o no mural.

Divida os alunos em duplas para que realizem a atividade "Texto quebracabeça" (Atividade I). O objetivo dessa atividade é verificar a capacidade de ordenar os acontecimentos seguindo os momentos da narrativa de forma a garantir a progressão textual. Selecionamos a parte inicial do conto "Coco Verde e Melancia" (AZEVEDO). [...]. (SENE, 2019, p. 16-17).

\section{Atividade $\mathbf{H}$}

Leitura do conto: "Moço bonito imundo" (AZEVEDO).

O texto que nós acabamos de ler foi organizado a partir de uma sequência de acontecimentos chamada de momentos da narrativa. Assim como o enredo é estruturado pelas ações que ocorrem na narrativa, os momentos da narrativa constituem o enredo. 
Os momentos de uma narrativa podem ser organizados da seguinte forma: situação inicial, conflito, clímax e desfecho. Um texto narrativo passa, necessariamente, por esses momentos para que ele se constitua como uma trama interessante para o leitor.

Vamos entender melhor relacionando o texto narrativo à uma montanha russa: Seria emocionante uma montanha-russa em linha reta, em que o carrinho andaria sempre na mesma direção, do mesmo jeito? Acredito que sua resposta tenha sido: NÃO! Da mesma forma, o texto narrativo se torna chato e monótono quando não desenvolve o conflito. $O$ texto precisa progredir! [...]

1. Identifique no conto "Moço bonito imundo" os acontecimentos correspondentes a cada um dos momentos da narrativa. Complete o quadro abaixo registrando uma síntese desses acontecimentos: [...] (SENE, 2019, p. 44-46).

\section{Atividade I}

Recorte as partes do texto e cole-as ordenando para que o texto siga uma sequência narrativa. Em seguida, nomeie as partes do texto de acordo com os momentos da narrativa: situação inicial, conflito, clímax e desfecho. [...] (SENE, 2019, p. 46).

Vale ressaltar que a oficina 6 , no processo de implementação, foi a que mais exigiu acompanhamentos e construção de novas atividades. Por diversas vezes foi preciso realizar releituras dirigidas dos textos; A reflexão sobre os elementos que formam a narrativa, mostrou-se como algo novo para aos alunos, apesar deles já terem, segundo nossa experiência docente, entrado em contato com a sequência da narração em muitos momentos, nos anos anteriores de escolaridade, na leitura de contos de fada, lendas, contos maravilhosos, etc. Foram necessários exercícios e ações para desconstruir estereótipos e apresentar nomenclaturas e conceitos até então desconhecidos pelos discentes, como: enredo, conflito, clímax, desfecho, protagonista, antagonista, entre outros. Contudo, a intenção não foi a de que os alunos soubessem identificar as partes do texto e/ou classificar partes, mas compreender como a organização dos elementos da narrativa contribuem para a construção dos sentidos do texto.

Tais atividades contribuíram para o desenvolvimento das capacidades discursivas (BARROS, 2012) dos alunos, como pode ser observado no exemplar transcrito. Os alunos estruturam os textos a partir daquilo que é regularidade do gênero conto maravilhoso (BAKHTIN, 2003).

A Oficina 9. Desenvolvendo o conto - teve como objetivo ampliar o léxico dos alunos relacionado ao universo maravilhoso; estimular a criatividade na composição dos personagens. Atividades: 1. Ampliação do léxico relacionado ao universo maravilhoso por meio da dinâmica "ABC do Era uma vez" (Banco de palavras - adaptação de técnicas da EC); 2. Composição dos personagens a partir da caracterização e da elaboração de descrição, pela dinâmica "Festa à fantasia" (adaptação de técnicas da EC); 4. Configuração dos personagens. Sugestão: 
Professor: [...] A primeira atividade parte do pressuposto de que o texto literário distingue-se do discurso cotidiano, dentre outros aspectos, pelo tratamento dado à linguagem (PAVANI; MACHADO, 2003). Pavani e Machado (2003, p. 30) defendem que "a linguagem literária ultrapassa o sentido convencional das palavras", e, por esse motivo, a atividade baseada em técnicas de EC atenta para os efeitos de sentido e as possibilidades de interpretação do texto provocados pela escolha lexical.

Explique aos alunos que os contos maravilhosos, por estarem inseridos no mundo da imaginação, utilizam palavras peculiares que fazem a diferença na construção do sentido do texto. Como exemplo, cite o efeito de sentido provocado pela substituição de CASA por CASEBRE, ou a simbologia que a palavra ESPELHO carrega. Então, entregue a eles a Atividade M, que tem por objetivo ampliar o léxico em relação ao universo maravilhoso e compor um banco de palavras para consulta a ser fixado no mural.

Para tornar a atividade mais dinâmica, o professor pode sugerir que os alunos participem de um jogo onde, agrupados em duplas ou trios, preencham a lista de palavras. Quando todos os grupos tiverem terminados medeie o processo de conferência, pontuando com 5 pontos palavras que se repetiram em mais grupos e com 10 pontos palavras exclusivas do grupo. Aquelas palavras que não têm relevância para a construção do maravilhoso não pontuam. Ao final somar a pontuação e premiar a equipe vencedora.

O objetivo desta atividade é estimular a criatividade dos alunos na composição das personagens principais (protagonista/antagonista) do conto que irão escrever. Para tanto é necessário previamente retomar a função dessas personagens no desenvolvimento do enredo do conto. Entregue aos alunos a Atividade $\mathbf{N}$ e conduza a discussão proposta. Em seguida, explique que farão uma apresentação para a turma, quando deverão vir caracterizados de acordo com as personagens que a dupla criou. Ainda na Atividade $\mathrm{N}$ há um espaço para que descrevam as características dessas personagens. No dia estipulado para a apresentação os alunos deverão apresentar-se como as personagens que criaram e descreverem-nas para a turma que poderá sugerir adaptações.

Pavani e Machado (2003, p. 47) afirmam que "no texto literário, a personagem revela-se o eixo em torno do qual gira a ação [...]"; por esse motivo, de acordo com a EC, trabalhar em sua caracterização direciona a construção da narrativa. (SENE, 2019, p. 19-21).

\section{Atividade M}

A tarefa de vocês é elaborar uma lista de palavras que remetam ao universo dos contos maravilhosos. Pode ser palavras que caracterizem a personagem, o lugar, as ações, enfim... qualquer palavra que pode ser utilizada para criar o maravilhoso/fantástico nos contos autorais.

A de

B de

[...] 
Vamos compartilhar com a turma as palavras que você listou? Elas podem fazer parte de um banco de palavras a ser fixado no mural. Utilize-as para melhor o seu conto!

\begin{abstract}
Atividade N
Você aprendeu que nos contos maravilhosos as personagens classificam-se de acordo com o papel que desempenham na história. A que desempenha o papel principal é protagonista, que costuma ser um herói ou uma heroína. A personagem que se opõe ao protagonista, seja porque sua ação atrapalha a do protagonista, seja porque suas características pessoais são opostas as daquele, é antagonista, que é o vilão ou a vilã da história.

Conhecemos os protagonistas e antagonistas também pelos aspectos físicos (altura, cor de cabelo, pelo, olhos, beleza ou não, etc.) e pela maneira de agir e pensar (medroso, esperto, bravo, caridoso, etc.).

Vamos conhecer as personagens dos contos que serão produzidos em sala? Para isso, caracterize-se como a personagem de seu conto. Vale usar fantasia, maquiagem, enfim, a criatividade para mostrar aos colegas como é sua protagonista ou antagonista principal. (SENE, 2019, p. 57-58).
\end{abstract}

A Oficina 9 tomou como objeto de ensino e aprendizagem alguns dos elementos que formam o nível linguístico-discursivo do texto, envolvidos no desenvolvimento das capacidades linguísticas dos alunos (BARROS, 2012). O intuito, no entrelaçamento com a EC, foi o de estimular a criação literária, uma vez que o conto maravilhoso situa-se no universo ficcional composto por espaços, seres e acontecimentos mágicos, assim, era importante que os alunos tivessem repertório lexical para compor suas histórias de forma coerente com o ambiente maravilhoso. Sendo assim, a composição do Banco de palavras, bem como a caracterização das personagens funcionaram como uma porta de entrada para o universo maravilhoso, no qual os alunos puderam desenvolver suas narrativas. A função das palavras na construção do sentido do texto foi apreendida pelos alunos. Dessa forma, os espaços escolhidos para o desenvolvimento das narrativas situaram-se no mundo imaginário típico dos contos maravilhosos.

Em relação às personagens, o trabalho baseado em técnica da EC propiciou a caracterização, além de reforçar a presença da disputa do bem contra o mal, materializada pela figura das personagens antagonista e protagonista: o samurai e a morte; a princesa corajosa e o homem de capuz e roupa preta, etc.

A seguir, transcrevemos uma das produções finais de autoria de um dos alunos participantes do projeto de intervenção didática, realizada em uma escola da rede pública de ensino da região norte do Paraná.

\title{
A princesa guerreira
}

Era uma vez uma princesa muito corajosa que morava em um reino distante. Ela amava jogas de ação, mas os homens da aldeia e de todo o reino tinham uma regra que mulheres não podiam guerrear. Mesmo assim a princesa sempre correu atrás dos seus objetivos de batalhar.

Certo dia ela se deparou com um cartaz que dizia: "Quem for a primeira pessoa a pegar a espada dourada que se encontra dentro da Caverna Dragons, irá ganhar um milhão em 
moedas de ouro e entrará na equipe dos gladiadores como capitão".

A princesa pensou um pouco e lembrou que a Caverna Dragons era umas das mais perigosas cavernas do mundo, mas como sempre ela criou coragem e foi.

Chegando na embarcação que iria levar os homens para a ilha não deixaram ela entrar e disseram:

-Mulheres não vão!

Mas ela insistiu que queria ir, então pulou e se agarrou em uma corda pendurada fora do barco e assim foram.

Se aproximando da ilha ela esperou todos os rapazes saírem do barco para que ninguém a visse descer. Muito rápido ela pulou e foi correndo por uma trilha. Como ela já conhecia aquela ilha, foi por um atalho.

Aquele atalho passava pela floresta tenebrosa e assustadora mas como a princesa era muito habilidosa, passou com segurança. Ao entrar na caverna avistou umas madeiras jogadas no chão e logo correu para tentar bloquear a entrada e tudo ficou escuro, não enxergava nada mais. Por sorte ela tinha trazido um lampião e assim foi caminhando. Até que, lá dos fundos da caverna ouviu uma voz lhe chamando:

-Venha, venha aqui.

Ao se aproximar viu que era um velho mago que estava ali há mais de dez anos preso pelo dragão. O mago perguntou:

-O que lhe traz aqui, minha hovem?

-Eu vim em busca da espada dourada.

Ele nem falou nadam apenas mirou para atrás e a trouxe uma espada linda feita de ferro, era muito afiada. Entregando a espada para a princesa ele disse:

-Use esta com sabedoria, ela pode ser boa em alguns sentidos, mas para algumas pessoas não! E tome cuidado com muitas armadilhas por ai.

Continuando seu caminho, parou um pouco para descansar, por azar pisou em um botão que disparou diversas flechas em sua direção, sem ter o que fazer saiu correndo e tinha saído de perigo, escutou passar caminhando atrás dela. Quando olhou para atrás um homem com um capuz e roupa preta lhe tacou uma flecha em suas costas e para piorar, a flecha estava envenenada, a pobre menina correu para se salvar.

Depois de alguns minutos correndo, tropeçou em uma linha que foi fechando o chão e o teto contra ele. Para escapar tinha um túnel com fumaças saindo e outro muito tenebroso e escuro. Mesmo com receio do escuro, escolheu aquele túnel e logo percebeu que havia entregado na toca do dragão. Por sorte o dragão estava dormindo. Ela percebeu que atrás dele tinha uma pequena porta trancada, então foi correndo procurou a chave e não achou, ao tropeçar em uma pedra acordou o aninal.

-Socorro, socorro!! - a princesa gritou.

Seu grito fez um eco que o velho mago escutou, então foi se teletransportando para vários túneis a procura dela. Ao chegar onde ela estava a encontrou desmaiada.

-Acorde princesa! Você precisa pegar a espada! - suplicou o mago.

Ao perceber que a moça não acordava, não viu outro jeito senão dar a ela uma poção de cura. Ao tomar a poção a princesa acordou.

O mago muito habilidoso entrou rapidamente na boca do dragão e retirou a chave da garganta dele. A princesa corajosa usou a espada para matar o animal e entro abriu a porta mágica que os levou direto para a aldeia.

Chegando lá todos ficaram de olhos arregalados, espantados por ser uma mulher que estava voltando com a espada. A princesa vitoriosa subiu em uma das casas para poder ser 
vista pela multidão e disse: iguais!

-Essa minha batalha foi para provar que homens não são superiores, que somos todos

Dessa forma ela venceu o desafio, ganhou as moedas de ouro e conseguiu realizar seu sonho de ser a capitã do time de gladiadores.

\section{CONSIDERAÇÕES FINAIS}

A comunhão entre as duas metodologias propiciou o desenvolvimento de capacidades de linguagem dos alunos uma vez que o gênero foi abordado em sua globalidade. A metodologia da SDG contribuiu à medida que propôs um conjunto de atividades, com objetivos delimitados, organizado e sistematizado com a finalidade de aprimorar as práticas linguageiras. Já a EC nos forneceu técnicas e preceitos que incentivaram o desenvolvimento da imaginação e da criatividade do aluno, imprescindível para a composição do conto maravilhoso.

Essa composição do material didático, com atividades organizadas de modo a articular os três níveis de capacidades de linguagem, fez com o que os alunos entrassem em contato com um gênero que, apesar de não ser uma novidade, trouxe novas perspectivas de leitura e produção. Especificamente no que se refere à capacidade de ação, percepções acerca do suporte, ambiente de circulação, valor e função social, enunciador, destinatário, enfim, o contexto de produção do gênero, favoreceram o reconhecimento do texto como manifestação de uma prática discursiva. Fica registrado o encantamento dos alunos ao conhecerem uma escritora com livros publicados e, posteriormente, a satisfação deles os tornarem-se escritores com a divulgação dos seus textos para a comunidade escolar.

Esperamos com esse trabalho colaborar com os demais professores da educação básica em atividades que possam desenvolver as capacidades de linguagem dos alunos, uma vez que nossa proposta pode ser adaptada, transformada, ampliada, ressignificada diante de outros objetivos, contextos, participantes.

\section{REFERÊNCIAS}

BAKTHIN, M. Estética da Criação Verbal. Trad. Paulo Bezerra. 4 ed. São Paulo: Martins Fontes, 2003.

BARROS, E. M. D. de. Gestos de ensinar e de aprender gêneros textuais: a sequência didática como instrumento de mediação. 2012. 370 fls. Tese (Doutorado em Estudos da Linguagem) - Universidade Estadual de Londrina, Londrina, 2012.

BRASIL. Base Nacional Comum Curricular. Brasília, MEC/CONSED/UNDIME, 2017. Disponível em: http://basenacionalcomum.mec.gov.br/wp-content/uploads/2018 /02/bncc-20dez-site.pdf Acesso em: 12 mar. 2018.

CANDIDO, A. O direito à literatura. In: Vários escritos. 5. ed. Rio de Janeiro: Ouro sobre Azul, 2011, p. 171-193.

COELHO, N. N. O conto de fadas. São Paulo: Ática, 1987.

COELHO, N. N. O conto de fadas: símbolos mitos arquétipos. São Paulo: DCL, 2003.

CRISTOVÃO, V. L. L. Sequências didáticas: semelhanças e especificidades no contexto francófono como L1 e no contexto brasileiro como LE. In: SZUNDY, P. T. C.; ARAÚJO, J. C.; NICOLAIDES, C. S.; SILVA, K. A. (Org.). Linguística Aplicada e 
sociedade: ensino e aprendizagem de línguas no contexto brasileiro. Campinas: Pontes Editores, 2011.

DOLZ, J.; SCHNEUWLY, B. Gêneros e progressão em expressão oral e escrita: elementos para reflexões sobre uma experiência francófona. In: SCHENEUWLY, B. e DOLZ, J. Gêneros orais e escritos na escola. Campinas: Mercado das Letras, 2004, p. 41-70.

GOMES, A. F. R.; SOUZA, S. S. Os módulos da sequência didática e a prática de análise linguística: relações facilitadoras. Revista (Con)textos Linguísticos: UFES, vol. 9, n. 14, 2015.

GUIMARÃES, A. M. M.; KERSCH, D. F. (org.). Caminhos da construção: projetos didáticos de gêneros na sala de aula de língua portuguesa. Campinas-SP: Mercado de Letras, 2012.

GUIMARÃES, A. M. M.; KERSCH, D. F. (org.). Caminhos da construção: projetos didáticos de gêneros no domínio do argumentar. Campinas-SP: Mercado de Letras, 2014.

GUIMARÃES, A. M. M.; KERSCH, D. F. (org.). Caminhos da construção: reflexões sobre projetos didáticos de gênero. Campinas-SP: Mercado de Letras, 2015.

LEITÃO, N. As palavras também saem das mãos. Revista Noesis online. Lisboa, n. 72, p. 30-33, jan./mar. 2008. Disponível em: www.oei.es/historico/pdfs/noesis72.pdf. Acesso em: 05 fev. 2018.

LOUSADA, E. O texto como produção social: diferentes gêneros textuais e utilizações possíveis no ensino-aprendizagem de LE. In: DAMIANOVIC, M. C. (Org). Material didático: elaboração e avaliação. Taubaté: Cabral, 2007. p. 33-43.

MACHADO, A. R. A perspectiva interacionista sociodiscursiva de Bronckart. In: MEURER, J. L.; BONINI, A.; MOTTA-ROTH, D. Gêneros: teorias, métodos, debates. São Paulo: Parábola Editorial, 2005, p. 237-259.

MACHADO, A. R.; CRISTOVÃO, V. L. L. A construção de modelos didáticos de gêneros: aportes e questionamentos para o ensino de gêneros. Revista Linguagem em (Dis)curso. v. 6, n. 3, p. 547-573, set./ dez. 2006.Disponível em: http://www.portaldeperiodicos.unisul.br/index.php/Linguagem_Discurso/article/view /349/370. Acesso em: 26 set. 2017.

MANCELOS, J. de. Introdução à escrita criativa. 4.ed. Lisboa: Colibri, 2013.

MIQUELANTE, M. A.; CRISTOVÃO, V. L. L.; PONTARA, C. L. (no prelo).

PONTARA, C. L.; CRISTOVÃO, V. L. L. Gramática/análise linguística no ensino de inglês (língua estrangeira) por meio de sequência didática: uma análise parcial. Revista Delta. vol. 33, n. 3, 2017, p. 873-909.

NASCIMENTO, E. L.; CRISTÓVÃO, V. L. L. Gêneros textuais e ensino: contribuições do interacionismo sócio-discursivo. In: KARWOSKI, A. M. (Orgs.). Gêneros textuais: reflexões e ensino. 3. ed. Rio de Janeiro: Nova Fronteira, 2008, p.2946.

PARANÁ, Secretaria de Estado da Educação. Diretrizes Curriculares da Rede Pública do Estado do Paraná - Lingua Portuguesa. Curitiba: SEED, 2008.

PAVANI, C. F.; MACHADO, M. L. B. Criatividade: Atividades de criação literária. Porto Alegre: UFGS, 2003. 


\section{$\log$

PROPP, V. Morfologia do conto maravilhoso. 2. ed. Rio de Janeiro: Forense Universitária, 2006.

SCHNEUWLY, B.; DOLZ, J. Gêneros orais e escritos na escola. Campinas: Mercado das Letras, 2004.

SENA-LINO, P. Curso de escrita criativa I. 3. ed. Porto: Porto Editora, 2013.

STRIQUER, M. dos S. D. A internalização dos gêneros textuais como instrumentos mediadores por professores em formação no PDE - Paraná. 2013. 439 f. Tese (Doutorado em Estudos da Linguagem) - Universidade Estadual de Londrina, Londrina, 2013.

SWIDERSKI, R. M. S.; COSTA-HÜBES, T. C. Abordagem sociointeracionista e sequência didática: relato de uma experiência. Língua \& Letras, Cascavel, v. 10, n. 18, 2009.

TAUVERON, C. A escrita "literária" da narrativa na escola: condições e obstáculos. Educar em Revista, n. 52, Curitiba, PR: Editora UFPR, p. 85-101, 2014.

Recebido em: 20/10/2019

Aprovado em: 07/12/2019

Publicado em: 19/12/2019 